\title{
Study of mir-141 and its Potential Targeted mRNA PTEN Expression in Nasopharyngeal Carcinoma: From in Silico to Initial Experiment Analysis
}

\author{
Duc Thuan Lao ${ }^{1,2^{*}}$, Danh Hoang Nguyen ${ }^{2}$ and Thuy Ai Huyen Le ${ }^{2}$ \\ ${ }^{1}$ Faculty of Biology and Biotechnology, University of Science, Vietnam National University Ho Chi Minh City, \\ Vietnam; ducthuanlao87@gmail.com, thuan.ld@ou.edu.vn \\ 2Faculty of Biotechnology, Ho Chi Minh City Open University, Ho Chi Minh City, Vietnam; \\ thuy.lha@ou.edu.vn
}

\begin{abstract}
Recently, accumulating evidences indicated that microRNA-141 (miR-141) is associated with NPC due to their abilities to affect the expression of genes that modulate tumorigenesis. Unfortunately, there is still limited publication about miR-141 expression in Vietnamese nasopharyngeal cancer patients. In this study, we adopted bioinformatics tools, such as Pictar, Target Scan, miRDB, etc. to predict its target gene. As the results, PTEN (phosphatase and tensin homolog gene), acts oncogenic role associated with biological processes lead to the nasopharyngeal carcinogenesis, was identified as the direct target of miR-141. Experimentally, we reported the evaluation of miR-141 and PTEN expression in NPC biopsy samples and non-cancerous swab samples. The present study demonstrated that miR-141 was upregulated 9.38 times, and PTEN expression was significantly lowered in NPC biopsy samples compared to non-cancerous epithelial swab samples. Our finding demonstrated that the miR-141 was upregulated and PTEN was down regulated in NPC biopsy samples. In the upcoming research, a larger clinical sample size from patients at each stage of the NPC will be performed to understand the expression pattern of the miR-141 and PTEN for further applied in early diagnosis and prognosis as well as therapeutic of NPC.
\end{abstract}

Keywords: miR-141, Nasopharyngeal Carcinoma, PTEN

\section{Introduction}

In Vietnam, NPC is the fifth most common cancer, resulting in 86,691 cases (Age-standardized rate-ASR $=1.2 / 100,000)$ and $50,831($ ASR $=0.7 / 100,000)$ deaths annually in Vietnam ${ }^{1,2}$. Although diagnosis of NPC has been improved in recent, most of NPC patients are still diagnosed with the advantage stage of NPC, due to ambiguous symptoms. Improved identification of potential biomarkers which promoting the NPC progression is not only essential for the development of new diagnosis strategies but also promising therapy. It is well known that miRNAs (micro RNAs) are short non-codingRNAmolecularwithin about20-23nucleotides (nts) in length that involved in post-transcriptional regulation of multiple genes ${ }^{3,4}$. miRNAs are highly conserved and widely detected in animals, plants, protists and viruses, that involved in numerous cellular processes including cell proliferation, differentiation, metabolism, stress response and apoptosis ${ }^{4,5}$. miRNAs control cell functions by binding to sequences in 3'-untranslated region (3'-UTR) of their target mRNAs, lead to turnover

${ }^{*}$ Author for correspondence 
and/or repression of mRNA expression ${ }^{3,4,6}$. In the past decades, growing evidences indicated that miRNAs have been implicated as both oncogenes and tumor suppressors that the abnormal expression (positive regulation or downregulation) of miRNAs contributes to various human tumor pathogenesis ${ }^{4,7-9}$. Overexpression of cancercausing miRNAs, known as onco-miRNAs, have been detected in various types of human cancers, including Nasopharyngeal Carcinoma (NPC), thus, represents not only therapeutic targets, but also pivotal biomarkers for cancer detection and management ${ }^{10-12}$. Among the known onco-miRNAs, miR-141, which is a member of the oncogenic miRNA clustered with miR-200c, located at 12p13.31 (nt: 6964097-6964191, [+]), stands out as the important role in human tumorigenesis ${ }^{13-17}$. However, numerous studies have shown the conflicting results regarding to whether the role of miRNA is an oncogenic miRNA or tumor suppressor miRNA in different types of cancer. Thus, determining the role of miR-141, especially on clinical specimens, leads to more understanding of cancers and the determination of potential diagnostic and prognostic biomarker as well as the therapeutic in clinical applications in different populations. In the case of miR-141 profile in NPC, only a few publications are reported. miR-141 is reported to be up-regulated in NPC specimens in comparison with normal nasopharyngeal epithelium, resulting in affecting cell cycle, apoptosis, cell growth, migration and invasion in NPC cells ${ }^{13}$. On the other hand, the prediction of its target gene, for which the target gene acts as an oncogene or a tumor suppressor gene, combined to miR-141, give a hand for development of the novel molecular target diagnosis and treatments. In previous studies, targets of miR-141 were identified, includes $B R D 3, P T E N$, and UBAP1, involved in a genemiR-141 network to contribute to NPC development ${ }^{13}$. Another report indicated that expression of miR-141 was also remarkably increased in NPC tissues and involved in BRD7-medidate cell progression and tumor formation through suppression of PTEN/AKT axis in nasopharyngeal carcinoma ${ }^{15}$. Therefore, miR-141 and its target gene expression profile has become an important tool to study the biomarker for prognosis and diagnosis as well as the therapeutic target for NPC. In this initial study, for further study of miR-141 and its target gene could be served as a potential biomarker for NPC in the Vietnamese population, we adopted many bioinformatics software to identify whether the targets of miR-141 is upregulated or downregulated, then, miR-141 and its target gene were experimentally identified from NPC biopsy samples and normal individuals.

\section{Materials and Methods}

\subsection{Patients' Samples Collection and Ethics Statement}

For the miRNA expression study, 20 NPC biopsy samples and 20 normal nasopharyngeal epithelium swab samples were enrolled into current study. Both samples were collected form patients in the Cho Ray Hospital. All samples were stored at $-20^{\circ} \mathrm{C}$ until further assays. All of those samples were submitted to the histopathological department, subsequently, were proved histologically to have NPC by Immunohistochemistry (IHC) confirmed. The NPC biopsy samples were positively confirmed as NPC by hematoxylin and eosin for histological examination (Figure 1).

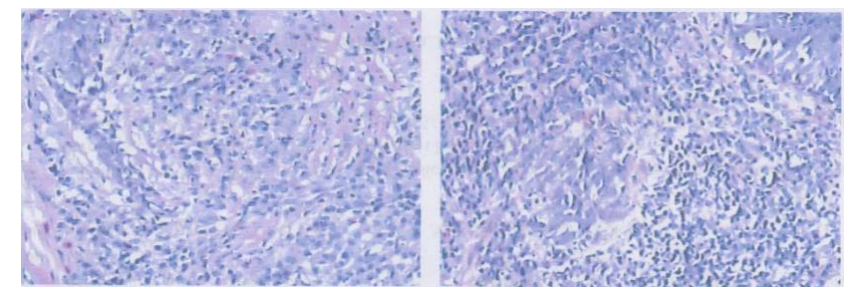

Figure 1. Histological examination of undifferentiated nasopharyngeal carcinoma.

Institutional Ethics Board approval was obtained from the Medical Ethics Committee of the Cho Ray Hospital, Ho Chi Minh City, Vietnam. (The decision number of the permission from Ethical committee: 516/BVCR-HDDD, Cho Ray Hospital, Ho Chi Minh City, Vietnam). All the samples used in this study were agreed by Cho Ray Hospital and obtained from all participants in current study. The patients are required to be agreed and sign on the consent forms.

\subsection{Bioinformatics Analysis}

The miRBase database (http://www.mirbase.org/) was used for finding out the basic information of miR-141. Possible target genes and signal pathways were validated by utilizing Pictar (https://pictar.mdc-berlin.de/), TargetScan 7.2 (http://www.targetscan.org/vert_72/), and miRDB (http://mirdb.org/), which identifies binding sites targeted by single miRNA.DAVID 2008 Functional Annotation Bioinformatics Microarray Analysis Tools 
(http://niaid.abcc.ncifcrf.gov/) was used to classify the functions of the target genes, which were predicted from Pictar, TargetScan 7.2 and miRDB online softwares. We used the Cancer Gene Census (https://cancer.sanger. ac.uk/cosmic/) and Tumor suppressor database (https:// bioinfo.uth.edu/TSGene/) to identify whether the target gene is an oncogene or a tumor suppressor gene.

\subsection{Total RNA Isolation, Reverse}

Transcriptase PCR Assay and Detection of

\section{miR-141 Expression}

miRNAs were isolated from NPC biopsy samples and non-cancerous samples by applying mirVana ${ }^{\mathrm{TM}}$ miRNA Isolation Kit (Ambion, Life Technology) according to the manufacturer's instructions. cDNA was reverse transcribed from approximately $5 \mathrm{ng}$ of Total RNA by using TaqMan ${ }^{\circledast}$ Advanced miRNA cDNA Synthesis Kit. The detection of miR-141 was determined by qualitative Real-time PCR (qRT PCR) assay with Taqman $^{\mathrm{TM}}$ Advanced miRNA assays kit (ThermoFisher Scientific). $5 \mu \mathrm{l}$ of RT reaction product was used to each reaction for detection of miR-141. The UniSp6 rRNA was used as the internal control candidate to normalize the $\mathrm{Ct}$ values because of the non-differential expression level in tumor and health adjacent samples.

\subsection{Evaluation of mRNA PTEN Expression}

For evaluation of PTEN expression, the detection of target cDNAs was determined by Reverse-Transcriptase PCR. cDNA from total of RNA template were generated by SensiFAST ${ }^{\mathrm{TM}} \mathrm{cDNA}$ Synthesis. The $\mathrm{cDNA}$ synthesis assay was performed by following steps: $25^{\circ} \mathrm{C}$ for $10 \mathrm{mins}, 42^{\circ} \mathrm{C}$ for $15 \mathrm{mins}, 85^{\circ} \mathrm{C}$ for $5 \mathrm{mins}$, and $4^{\circ} \mathrm{C}$ hold. The cDNA was stored at $-20^{\circ} \mathrm{C}$ for further PCR assay. The cDNA $G A P D H$ was used as the internal control candidate in this assay. The sequence of primers used in current study was shown in (Table 1).

\section{Statistical Analysis}

Data were analyzed using Medcalc ${ }^{\oplus}$ Version 12.7.0.0. All $\mathrm{p}$ values were two-side, and values less than 0.05 were considered significant. All values were reported as mean \pm SD. The relative expression of miR-141 as determined using q-PCR was analyzed using the $2^{-\Delta \Delta \mathrm{Ct}}$ method. Finding was greater and less than 1 was determined to classify up-regulation and down-regulation, respectively. Chi-test was used to determine the association between the expression of miR-141 and NPC status. Moreover, the association between expression of miR-141 and risk of NPC was estimated by computing OR (Odd ratios), RR (Relative risk) and 95\% Confidence Intervals (CI).

\section{Results}

\subsection{Bioinformatics Analysis of miR-141 and Putative Targets}

miR-141 is belonged to the miR-200c family, concludes five members: miR-200b, miR-200c, miR-429, miR141 and miR-200a, divided into two sub-families which classified based on the sequence homology in their seed regions, and the highly conversed nucleotides of miR141 is observed in many species, such as Pan troglodytes, Homo sapiens, Mus musculus, Rattus norvegicus, Macaca mulatta, Gorilla gorilla, Pongo pygmaeus, Pan paniscus, Monodelphis domestica ${ }^{17}$. The target genes are predicted by the online softwares, includes Pictar, TargetScan 7.2, miRDB. TargetScan predicted that 896 genes are possible targets of miR-141, Pictar predicted that 422 genes are possible targets, whereas miRDB predicts that 759 genes are target of miR-141. The functions of predicted genes, which were predicted from above three online softwares, were classified by using DAVID 2008 Functional Annotation Bioinformatics Microarray Analysis Tools. The results revealed that most target genes of miR-141 are involved in many signal pathways, which are considered

Table 1. The sequence of primers used in current study

\begin{tabular}{|c|c|c|c|}
\hline Gene & Primer & Sequences $\left(5^{\prime}-3^{\prime}\right)$ & Reference \\
\hline \multirow[t]{2}{*}{ PTEN } & Forward & CAGAAAGACTTGAAGGCGTAT & \multirow[t]{2}{*}{18} \\
\hline & Reversed & AACGGCTGAGGGAACTC & \\
\hline \multirow[t]{2}{*}{ GAPDH } & Forward & AATCCCATCACCATCTTCCA & \multirow[t]{2}{*}{19} \\
\hline & Reversed & CCTGCTTCACCACCTTCTTG & \\
\hline
\end{tabular}


to be important role in tumorigenesis, such as: cell cyle, p53 signaling pathway, tight junction, Wnt signaling pathway, MAPK signaling pathway, Jak-STAT signaling pathway, etc. (Figure 2).

In the list of miR-141-targert genes, PTEN (phosphatase and tensin homolog gene) was attracted our attention. Cancer Gene Census and Tumor suppressor database were used to identify the whether PTEN is a suppressor gene or an oncogene. As the result, PTEN is tumor suppressor gene in human cancer. PTEN encoded protein inhibits the activity of PI3K and then acts as a vital of tumor suppressor gene, that involved in multiple biological processes such as cell growth, proliferation, metabolism, apoptosis, etc... Additionally, PTEN regulates p53 protein levels and activity through phosphatasedependent and -independent mechanisms. Hallmark page, based on the Cancer Gene Census analysis, explains the role of PTEN in cancer by highlighting, which of the classic behavior are displayed by the gene product and whether they are promoted or suppressed (Table 2).

Confirmed the reliability of PTEN is the target gene of miR-141, consequential pairing of 3 '-untranslated region of PTEN and miR-141-3p were performed by TargetScan 7.2. The results revealed that the site type of binding between miR-141-3p and PTEN 3'-UTR were 7mer-m8, 7mer-A1 (Table 3).

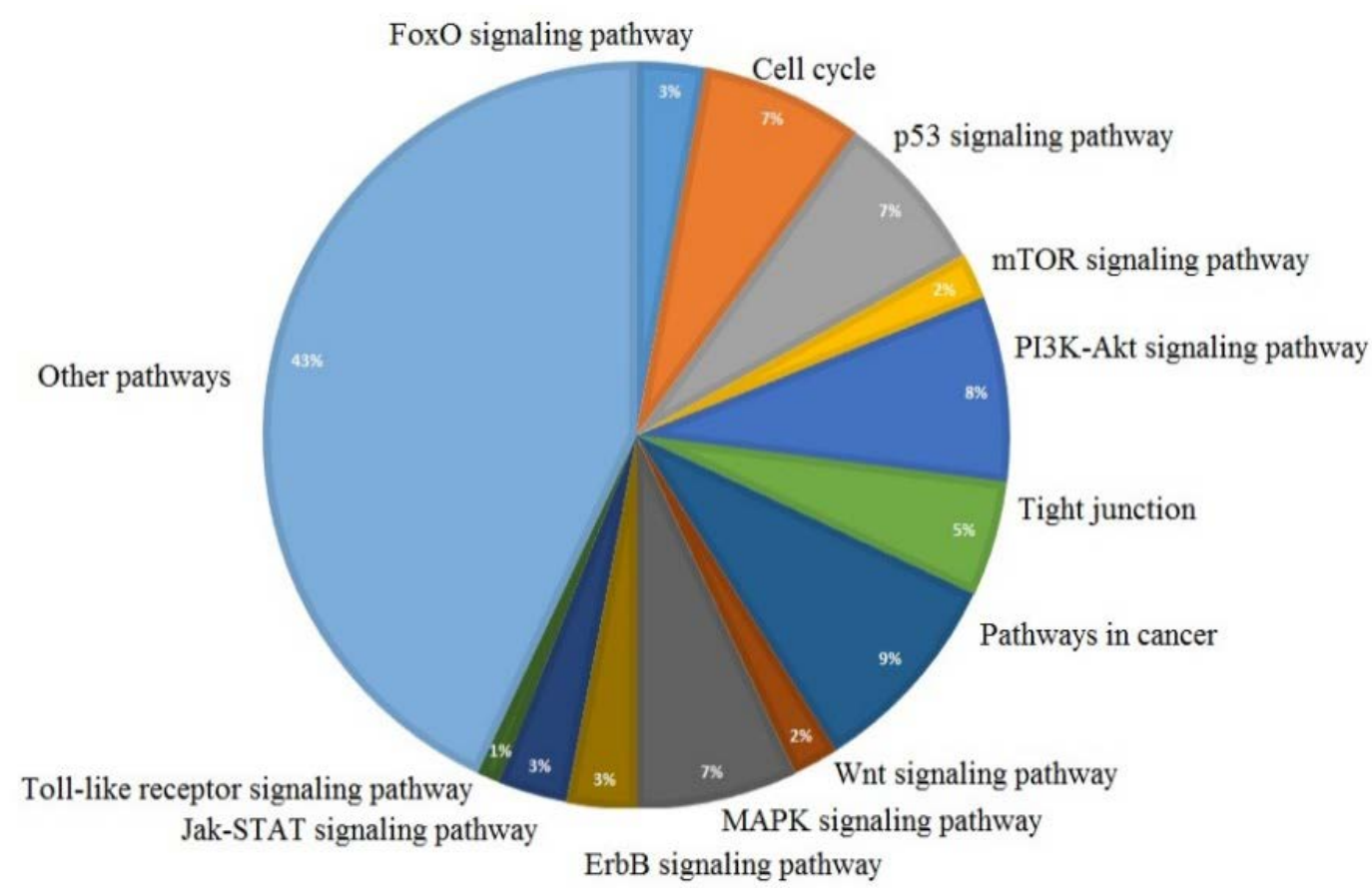

Figure 2. Functions of predicted miR-141 target genes.

Table 2. A concise overview of cancer hallmark of PTEN with associated references

\begin{tabular}{|l|c|c|}
\hline Hallmarks & Promote or Suppress & Reference \\
\hline Suppression of growth & Promote & $20-22$ \\
\hline Escaping immunic response to cancer & Suppress & 23 \\
\hline Cell replicative immortality & Suppress & 25,26 \\
\hline Invasion and metastasis & Suppress & 27,28 \\
\hline Genome instability and mutations & Suppress & 29,30 \\
\hline Escaping programmed cell death & Suppress & 31,32 \\
\hline Change of cellular energetics & Promote & \\
\hline
\end{tabular}


Table 3. Predicted conserved consequential pairing of miR-141 and PTEN 3'-UTR

\begin{tabular}{|c|c|c|}
\hline $\begin{array}{l}\text { Position of miR-141 binding } \\
\text { PTEN 3'-UTR }\end{array}$ & $\begin{array}{l}\begin{array}{l}\text { Predicted consequential pairing of PTEN (top) and miR-141-3p } \\
\text { (bottom) }\end{array} \\
\end{array}$ & Site type \\
\hline $1467-1473$ & $\begin{array}{c}5^{\prime} \ldots \text {...UUUUUUUUUAAAUGUGCAGUGUUG. . . } \\
\qquad{ }^{\prime} \quad \text { GGUAGAAAUGGUCU-GUCACAAU }\end{array}$ & 7 mer-m8 \\
\hline $3257-3263$ & 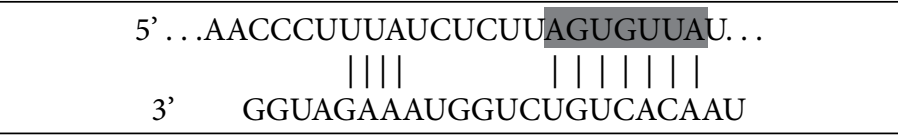 & 7mer-A1 \\
\hline $4252-4258$ & 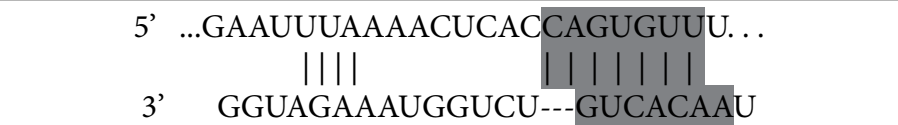 & 7mer-m8 \\
\hline
\end{tabular}

Note: the binding site was in black frame

\section{2 miR-141 was Higher Expression in NPC Biopsy Samples}

cDNA U6 (UniSp6 rRNA) was used as internal control for the evaluation of miR-141 expression in the comparison between the NPC group (case group) and non-cancerous group (control group). The cDNA U6 was positive in both the case and control group by Real-time PCR, the Ct value of cDNA U6 were $30.55 \pm 0.63$ and $30.55 \pm 0.75$ in the case and control group, respectively. The $\mathrm{p}$ value $(\mathrm{p}=$ $0.86>0.05$ ) indicated the expression of $\mathrm{U} 6$ was no difference between those two groups (Figure 3A). In current study, the proportion of miR-141 expression in NPC and noncancerous samples were detected by qRT-PCR. The positive rate of miR-141 was $40 \%$ ( 8 of 20 cases) and $10 \%$ ( 2 of 20 cases) in case and control group, respectively. The $\mathrm{p}$ value $(\mathrm{p}=0.03)$ indicated the significant correlation between the miR-141 expression and NPC. The results of odds ratio and relative risk values were $6.00(95 \% \mathrm{CI}=$ 1.08 to 33.28$), 2.00$ (95\% CI $=1.17$ to 3.42 ), respectively. The mean of Ct value of miR-141 expression in the case and control group were $27.27 \pm 1.14$ and $34.50 \pm 2.72$, $(\mathrm{p}=0.0116)$ (Figure 3B). The relative quantification of miR-141 expression between the case group and control group was analyzed by the $2^{-\Delta \Delta \mathrm{Ct}}$ method, as the result, the expression of miR-141 levels was 9.38 times $(p=0.003)$ higher in tumor samples in comparison with the noncancerous samples $(\mathrm{p}=0.022)$ (Figure 3C).

\subsection{PTEN was Downregulated in NPC Biopsy Samples}

To access whether PTEN is upregulated or downregulated in case group, we explored the relationship between the

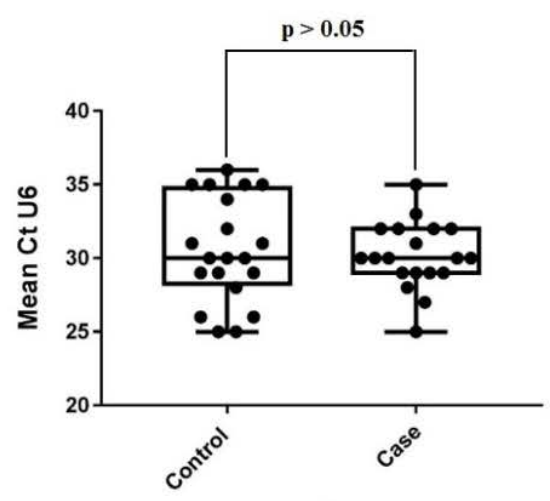

(A)

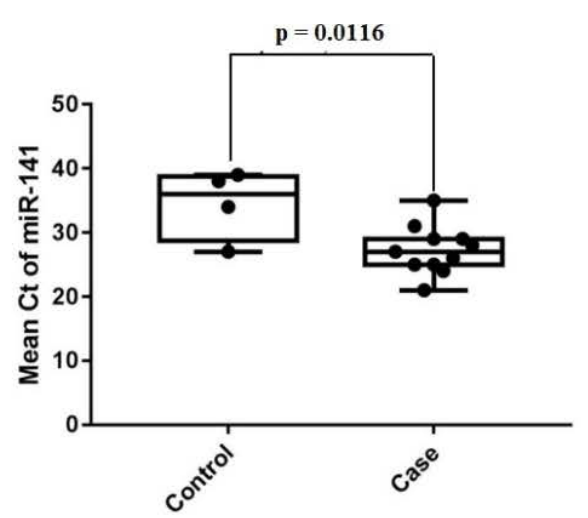

(B)

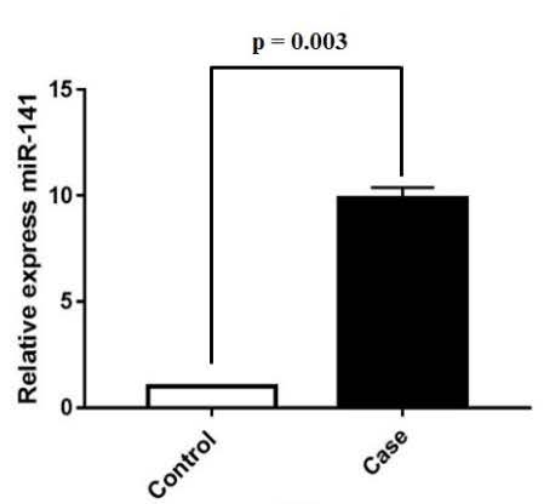

(C)

Figure 3. The mean of Ct value (mean \pm SE) of (A) UniSp6 rRNA; (B) miR-141 in the case group and control group. Each black dot was indicated the Ct value of each sample; (C) qRT-PCR showed the level expression of miR-141 was up-regulated in NPC biopsy samples compared with the non-cancerous samples. 
expression of PTEN in biopsy samples and non-cancerous samples by Reverse-transcriptase PCR. The PCR products obtained in distinctly size, yielded a PCR product of 625 bps (Figure 4A). The amplification of PTEN was determined by Sanger sequencing. As the result, the sequenced results of target genes indicated the clear and single peak of each nucleotide (Figure $4 \mathrm{~B}$ ). According to BLAST results, candidate gene sequence was similar to Homo sapiens Phosphate and Tensin homolog (PTEN), mRNA within accession number: NM_001304717, Total score $=939$, Ident $=98 \%$, e-value $=0.0$. The examination showed that the proportion of positive PTEN were $45.0 \%$ (9 of 20 cases) and $85.0 \%$ ( 17 of 20 cases) in case and control group, respectively. The $\mathrm{p}$ value $(\mathrm{p}=0.02)$ indicated the significantly higher rate in control group than in the case group. The results of odds ratio and relative risk values were 0.14 ( $95 \% \mathrm{CI}=0.03$ to 0.65$), 0.44$ (95\% CI $=0.2430$ to 0.7987 ), respectively. Those results indicated that the expression of PTEN may serve as the tumor suppressor genes by reduction of odds ratio and relative risk.

\section{Discussion}

NPC is the most common cancer originated from the nasopharynx with high occurrence in Southern China and Southern Asia. According to the global registry of cancer incidence and mortality, NPC ranked $5^{\text {th }}$ among all malignancies in Vietnam. Up to date, accumulating evidences indicated the dysregulation of miRNAs has crucial roles in the progression of multiple cancers ${ }^{3,4,7,33}$. The dysregulation of miR-141, located on chromosome 12p13.31, was observed in wide range of human cancers, nasopharyngeal carcinoma, hepatocellular carcinoma, colon cancer, prostate cancer, bladder cancer, ovarian cancer, breast cancer, etc. ${ }^{17}$, acting the dual roles either as oncogene or as tumor suppressor via several molecular mechanisms. In current study, we confirmed that miR-141 is expressed significantly higher in NPC biopsy samples in the comparison with non-cancerous nasopharyngeal epithelial swab samples by qRT-PCR. The positive rate of miR-141 expression in NPC biopsy samples was $40.0 \%$ (Sensitivity $=40.0 \%$ ), it implied that the characteristic of $40.0 \%$ of NPC biopsy samples will be positive of miR-141 expression, compared to $10.0 \%$ of non-cancerous swab samples. The $2^{-\Delta \Delta \mathrm{Ct}}$ value $\left(2^{-\Delta \Delta \mathrm{Ct}}=\right.$ 9.38 ) is once confirmed that the overexpression of miRNA levels was once confirmed by 9.38 times higher in tumor samples in comparison with the non-cancerous sample. The up-regulation of miR-141 was strongly correlated with NPC risk with the significant statistic through the calculating the RR and OR $(p<0.05)$ The odds for a positive expression of miR-141 in NPC was 6.00 times higher than in the case of cancer without expression of miR-141 ( $\mathrm{OR}=6.00,95 \% \mathrm{CI}=1.08$ to 33.28$)$. Additionally, the expression of miR-141 was 2.00 times higher than no miR-141 expression in NPC $(\mathrm{RR}=2.00,95 \% \mathrm{CI}=$ 1.17 to 3.42 ). Thus, all of these results imply that, even though the limit amount of samples enrolled in current study, miR-141 might play a pivotal role as oncogene in NPC tumorigenesis. Compared to previous studies, the up-regulated expression of miR-141 was also observed in NPC samples, which were obtained from The Second Xiangya Hospital of Central South University (Changsha, China), The Second Xiangya Hospital and Hunan Province Tumor Hospital, and NPC cell lines compared

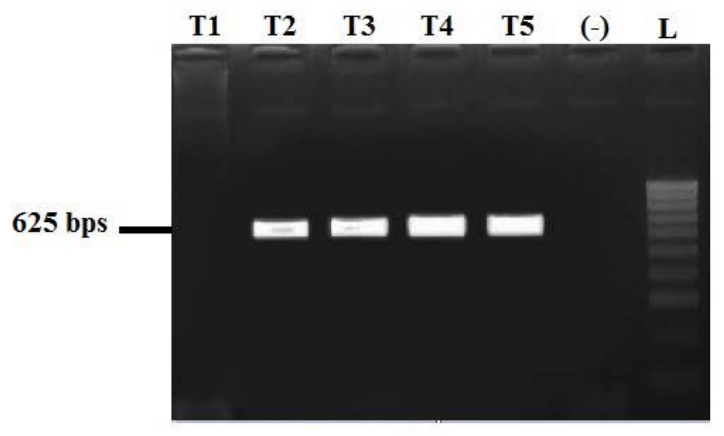

(A)

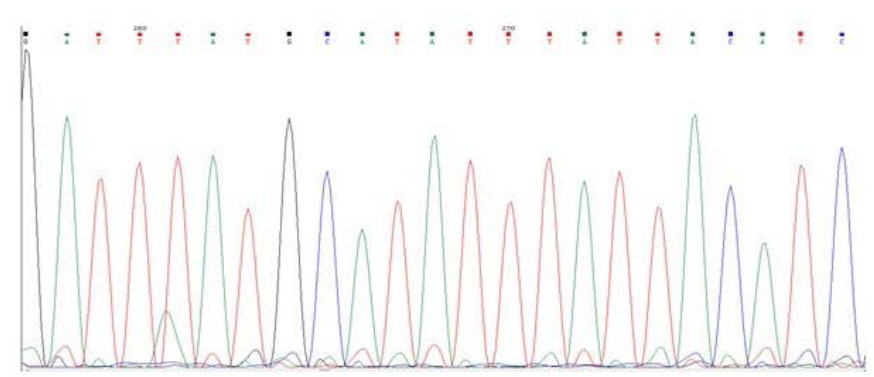

(B)

Figure 4. (A) Agarose gel electrophoresis of the PCR products of representative NPC biopsy samples. (-): negative control; L: 100-bps DNA marker. (B) The part of cDNA sequencing of PTEN in representative sample. 
to non-cancerous samples ${ }^{13,15,34}$. Notably, in Vietnam, no study about of miR-141 in NPC has been reported. This is a follow-up study on previous findings in the application of using biopsies to assess miRNA properties. Therefore, this study was the first case-control study that we focus on the evaluation of miR-141 profile in local NPC patients. By the prediction of bioinformatics tools, such as Pictar, TargetScan, miRDB, a wide range of possible target genes of miR-141, which are linked to many signaling pathways considered to be important role in tumorigenesis, were predicted. Bioinformatics analysis results showed PTEN confirmed that PTEN act as direct target of miR-141 through the consequential pairing of 3 '-untranslated region of PTEN and miR-141-3p, includes 7mer-8, 7merAl site type. With the prediction of Cancer Gene Census and Tumor suppressor database, PTEN acts as a tumor suppressor gene, that involved in multiple biological processes lead to the carcinogenesis, based on the analysis of cancer hallmark. The relationship between miR-141 and PTEN to contribute to NPC development has been reported. According to Zhang et al., the expression of miR-141 may increase the phosphorylation of AKT, which mechanism plays an important role to result in the activation of cascade of several proteins involved in cell proliferation, invasion and promote tumorigenesis. Notably, the ATK phosphorylation levels are increased by miR-141 through the inhibition of PTEN expression ${ }^{13}$. Therefore, understanding of both expression of miR-141 and PTEN may lead to find out possible prognosis and early diagnosis biomarkers for NPC. In current study, the expression of PTEN in both case and control group were determined by RT-PCR. As the results, the expression of PTEN in NPC biopsy samples with the lower positive rate of $45.0 \%$ compared to the positive rate in non-cancerous swab samples with the rate of $85.0 \%$. The downregulation of PTEN in NPC samples increased the risk of NPC through the OR and RR value. This observation was similar to previous studies that PTEN is downregulated in NPC samples. Therefore, based on those results, we implied that miR-141 is the negative regulator of PTEN. Finally, we suggested that the same concept of miR-141 role with previous studies is that: miR-141 was up-regulated, acted as an oncogenic role, and also reported as negative regulator of PTEN, acted as an tumor suppressor in NPC. For further study, identification of miR-141 as well as PTEN expression in larger amount samples, as well as the non-invasive specimens, to characterize the miR-141 and PTEN expression profile and severed as the biomarkers for the screening and early diagnosis of NPC in Vietnamese population, will be continuously studied.

\section{Conclusion}

In summary, we demonstrated that PTEN is the direct target gene of miR-141, which was confirmed by bioinformatics tools prediction, multiple biological processes lead to the nasopharyngeal carcinogenesis. Experimentally, we confirmed that miR-141 was upregulated 9.38 times in NPC samples compared with the non-cancerous samples. The percentage of miR-141 detection in cancerous and non-cancerous samples were $40.0 \%$, and $10.0 \%,(\mathrm{p}=0.03)$, respectively. Additionally, PTEN was determined as the negative regulated by miR-141, in detail, the down-regulation of PTEN was observed in NPC samples compared to non-cancerous samples. Therefore, all of those findings suggest that the determination of both stage of miR-141 and PTEN might serve as possible biomarkers in the diagnosis and prognosis of NPC. In further research, the amount of samples have to be enlarged, as well as different stages of cancers, will increase the application of using miR-141 and PTEN properties in the diagnosis and prognosis of NPC.

\section{Acknowledgement}

We wish to express our thanks to the research project sponsored by Ho Chi Minh City Department of Science and Technology, Vietnam; Ho Chi Minh City Open University, HCMC, Vietnam. We also thank all the recruited participants in this work and Dr. Nguyen Trong Minh, Dr. Nguyen Huu Dung and all the staff members of Otorhinolaryngology in Cho Ray Hospital, Ho Chi Minh City, for collecting the samples used in these studies. We are thankful to Ngo Dong Kha, Thieu Hong Hue, Nguyen Hoang Nhat Minh, Quang Trong Minh, K' Trong Nghia, Hoang Van Nam for their assistances.

\section{Author's Contribution}

Thuan LD 35\%; Danh NH 30\%; Thuy LHA 35\%. All authors read and approved the final manuscript. 


\section{Ethics Approval and Consent to Participate}

All patients signed inform consent before entering into the study. No study drug or procedure was applied. This is an observational study.

\section{Conflict of Interest}

The authors declared that they have no competing interests.

\section{References}

1. GLOBOCAN. Estimated cancer incidence, mortality and prevalence worldwide in 2012; 2012. Available from: http:// globocan.iarc.fr/Pages/fact_sheets_population.aspx

2. Mahdavifar N, Ghoncheh M, Mohammadian-Hafshejani A, Khosravi B, Salehiniya H. Epidemiology and inequality in the incidence and mortality of Nasopharynx cancer in Asia. Osong Public Health and Research Perspectives. 2016; 7(6):360-72. https://doi.org/10.1016/j.phrp.2016.11.002 PMid:28053841 PMCid:PMC5194228

3. Croce CM, Calin GA. miRNAs, cancer, and stem cell division. Cell. 2005; 122(1):6-7. https://doi.org/10.1016/j. cell.2005.06.036 PMid:16009126

4. Bartel DP. MicroRNAs: Target recognition and regulatory functions. Cell. 2009; 136(2):215-33. https:// doi.org/10.1016/j.cell.2009.01.002

PMid:19167326 PMCid:PMC3794896

5. He L, Hannon GJ. MicroRNAs: small RNAs with a big role in gene regulation. Nat Rev Genet. 2004; 5(7):522-31. https://doi.org/10.1038/nrg1379 PMid:15211354

6. Bushati N, Cohen SM. microRNA functions. Annu Rev Cell Dev Biol. 2007; 23:175-205. https://doi.org/10.1146/ annurev.cellbio.23.090506.123406 PMid:17506695

7. Calin GA, Croce CM. MicroRNA signatures in human cancers. Nat Rev Cancer. 2006; 6(11):857-66. https://doi. org/10.1038/nrc1997 PMid:17060945

8. Ha M, Kim VN. Regulation of microRNA biogenesis. Nat Rev Mol Cell Biol. 2014; 15(8):509-24. https://doi. org/10.1038/nrm3838 PMid:25027649

9. Zhang B, Pan X, Cobb GP, Anderson TA. microRNAs as oncogenes and tumor suppressors. Dev Biol. 2007; 302(1):1-12. https://doi.org/10.1016/j.ydbio.2006.08.028

10. Hayes J, Peruzzi PP, Lawler S. MicroRNAs in cancer: Biomarkers, functions and therapy. Trends Mol Med. 2014; 20(8):460-9. https://doi.org/10.1016/j.molmed.2014.06.005 PMid:25027972
11. Kala R, Peek GW, Hardy TM, Tollefsbol TO. MicroRNAs: an emerging science in cancer epigenetics. J Clin Bioinforma. 2013; 3(1):6. https://doi.org/10.1186/2043-9113-3-6 PMid:23497588 PMCid:PMC3608239

12. Lee KT, Tan JK, Lam AK, Gan SY. MicroRNAs serving as potential biomarkers and therapeutic targets in nasopharyngeal carcinoma: A critical review. Crit Rev Oncol Hematol. 2016; 103:1-9. https://doi.org/10.1016/j. critrevonc.2016.04.006 PMid:27179594

13. Zhang L, Deng T, Li X, Liu H, Zhou H, Ma J, et al. microRNA-141 is involved in a nasopharyngeal carcinomarelated genes network. Carcinogenesis. 2010; 31(4):559-66. https://doi.org/10.1093/carcin/bgp335 PMid:20053927

14. Zuo QF, Zhang R, Li BS, Zhao YL, Zhuang Y, Yu T, et al. MicroRNA-141 inhibits tumor growth and metastasis in gastric cancer by directly targeting transcriptional co-activator with PDZ-binding motif, TAZ. Cell Death Dis. 2015; 6:e1623. https://doi.org/10.1038/cddis.2014.573

15. Liu Y, Zhao R, Wang H, Luo Y, Wang X, Niu W, et al. miR-141 is involved in BRD7-mediated cell proliferation and tumor formation through suppression of the PTEN/ AKT pathway in nasopharyngeal carcinoma. Cell Death Dis. 2016; 7:e2156. https://doi.org/10.1038/cddis.2016.64 PMid:27010857 PMCid:PMC4823963

16. Liu Y, Zhao R, Wei Y, Li M, Wang H, Niu W, et al. BRD7 expression and c-Myc activation forms a double-negative feedback loop that controls the cell proliferation and tumor growth of nasopharyngeal carcinoma by targeting oncogenic miR-141. J Exp Clin Cancer Res. 2018; 37(1):64. https://doi.org/10.1186/s13046-018-0734-2 PMid:29559001 PMCid:PMC5859396

17. Lao DT, Truong KP, Le HAT. miRNA-141 as the Biomarker for Human Cancers. AJPRHC. 2018; 10(2):42-9. https:// doi.org/10.18311/ajprhc/2018/21486

18. Sano T, Lin H, Chen X, Langford LA, Koul D, Bondy ML, et al. Differential expression of MMAC/PTEN in glioblastoma multiforme: relationship to localization and prognosis. Cancer Res. 1999; 59(8):1820-4. PMid:10213484

19. Li A, Zhang XS, Jiang JH, Wang HH, Liu XQ, Pan ZG, et al. Transcriptional expression of RPMS1 in nasopharyngeal carcinoma and its oncogenic potential. Cell Cycle. 2005; 4(2):304-9. https://doi.org/10.4161/cc.4.2.1416 PMid:15725729

20. Sun H, Lesche R, Li DM, Liliental J, Zhang H, Gao J, et al. PTEN modulates cell cycle progression and cell survival by regulating phosphatidylinositol 3,4,5,-trisphosphate and Akt/protein kinase B signaling pathway. Proc Natl Acad Sci U S A. 1999; 96(11):6199-204. https://doi.org/10.1073/ pnas.96.11.6199 PMid:10339565 PMCid:PMC26859

21. Mahimainathan L, Choudhury GG. Inactivation of plateletderived growth factor receptor by the tumor suppressor 
PTEN provides a novel mechanism of action of the phosphatase. J Biol Chem. 2004; 279(15):15258-68. https:// doi.org/10.1074/jbc.M314328200 PMid:14718524

22. ShindeSR, MaddikaS.PTEN modulates EGFRlate endocytic trafficking and degradation by dephosphorylating Rab7. Nat Commun. 2016; 7:10689. https://doi.org/10.1038/ ncomms10689 PMid:26869029 PMCid:PMC4754336

23. Peng W, Chen JQ, Liu C, Malu S, Creasy C, Tetzlaff MT, et al. Loss of PTEN Promotes Resistance to T Cell-Mediated Immunotherapy. Cancer Discov. 2016; 6(2):202-16. https:// doi.org/10.1158/2159-8290.CD-15-0283 PMid:26645196 PMCid:PMC4744499

24. Hill R, Wu H. PTEN, stem cells, and cancer stem cells. J Biol Chem. 2009; 284(18):11755-9. https://doi.org/10.1074/jbc. R800071200 PMid:19117948 PMCid:PMC2673242

25. Maier D, Jones G, Li X, Schönthal AH, Gratzl O, Van Meir EG, et al. The PTEN lipid phosphatase domain is not required to inhibit invasion of glioma cells. Cancer Res. 1999; 59(21):5479-82. PMid:10554022

26. Leslie NR, Yang X, Downes CP, Weijer CJ. PtdIns $(3,4,5)$ $\mathrm{P}(3)$-dependent and -independent roles for PTEN in the control of cell migration. Curr Biol. 2007; 17(2):115-25. https://doi.org/10.1016/j.cub.2006.12.026 PMid:17240336 PMCid:PMC1885949

27. Puc J, Parsons R. PTEN loss inhibits CHK1 to cause double stranded-DNA breaks in cells. Cell Cycle. 2005; 4(7):927-9. https://doi.org/10.4161/cc.4.7.1795 PMid:15970699

28. Shen WH, Balajee AS, Wang J, Wu H, Eng C, Pandolfi $\mathrm{PP}$, et al. Essential role for nuclear PTEN in maintaining chromosomal integrity. Cell. 2007; 128(1):157-70. https:// doi.org/10.1016/j.cell.2006.11.042 PMid:17218262

29. Li J, Simpson L, Takahashi M, Miliaresis C, Myers MP, Tonks $\mathrm{N}$, et al. The PTEN/MMAC1 tumor suppressor induces cell death that is rescued by the $\mathrm{AKT} /$ protein kinase $\mathrm{B}$ oncogene. Cancer Res. 1998; 58(24):5667-72. PMid:9865719

30. Xu Z, Stokoe D, Kane LP, Weiss A. The inducible expression of the tumor suppressor gene PTEN promotes apoptosis and decreases cell size by inhibiting the PI3K/Akt pathway in Jurkat T cells. Cell Growth Differ. 2002; 13(7):285-96. PMid:12133897

31. Pal A, Barber TM, Van de Bunt M, Rudge SA, Zhang Q, Lachlan KL, et al. PTEN mutations as a cause of constitutive insulin sensitivity and obesity. N Engl J Med. 2012; 367(11):1002-11. https://doi.org/10.1056/ NEJMoa1113966 PMid:22970944 PMCid:PMC4072504

32. Ortega-Molina A, Serrano M. PTEN in cancer, metabolism, and aging. Trends Endocrinol Metab. 2013; 24(4):184-9. https://doi.org/10.1016/j.tem.2012.11.002 PMid:23245767 PMCid:PMC3836169

33. Markopoulos GS, Roupakia E, Tokamani M, Chavdoula E, Hatziapostolou M, Polytarchou C, et al. A step-by-step microRNA guide to cancer development and metastasis. Cell Oncol (Dordr). 2017; 40(4):303-39. https://doi. org/10.1007/s13402-017-0341-9 PMid:28748501

34. Chen P, Guo X, Zhou H, Zhang W, Zeng Z, Liao Q, et al. SPLUNC1 regulates cell progression and apoptosis through the miR-141-PTEN/p27 Pathway, but is hindered by LMP1. Samant R, editor. PLoS ONE. 2013; 8(3):e56929. 